\title{
CIS FACULTY PERCEPTIONS OF THE IMPACT AND EFFECTIVENESS OF CLOUD COMPUTING TECHNOLOGY
}

\author{
Fahad Alfifi, Robert Morris University,faast219@mail.rmu.edu \\ Paul J. Kovacs, Robert Morris University,kovacs@rmu.edu \\ Saeed Q. Al-Maliki, King Khalid University, salkhalidi@kku.edu.sa \\ Wenli Wang, Robert Morris University, wangw@rmu.edu \\ Gary Alan Davis, Robert Morris University, davis@rmu.edu
}

\begin{abstract}
This study was undertaken to determine how Computer and Information Systems (CIS) faculty at two institutions of higher education view the use of cloud computing technology within their respective departments. One University is located in the Unites States and the other is located in Saudi Arabia. Specifically, this study sought to determine the perceptions of Computer and Information Systems faculty regarding cloud computing, the advantages and disadvantages of using cloud computing, and the key factors that influence the adoption and use of cloud computing.
\end{abstract}

Keywords: Cloud Computing, Virtualization, Information Systems Education, Information Systems Faculty

\section{INTRODUCTION}

Cloud computing can be described as a new generation of computing that allows an organization to enhance its information technology capacity. In other words, cloud computing is a new technology that combines virtualization, grid computing, and time-sharing [4]. Cloud computing has different definitions, which are based on the different services being offered, as well as, the type and size of the organization. Stroh [11] defined cloud computing as a companion of software and services that can be accessed using a high-speed Internet connection, instead of using traditional local servers. According to the National Institute of Standards and Technology (NIST), cloud computing is "a model for enabling ubiquitous, convenient, on-demand network access to a shared pool of configurable computing resources (e.g., networks, servers, storage, applications, and services) that can be rapidly provisioned and released with minimal management effort or service provider interaction" [20].

Cloud computing offers the following services:

1. On-demand self-services: the consumer performs their necessary operations to obtain the needed services without human intervention with each service provider, such as email, applications, server and network storage.

2. Broad network access: consumers are able to work from anywhere, at any time, through a browser, using standard mechanisms to install applications to access data, using an on-demand approach (e.g., mobile phones, tablets and laptops).

3. Resource pooling: consumers are able to access a pool of services using the multi-tenant model that provides provisional and scalable services. These services are assigned and reassigned according to customers' demands. Examples of resources include storage, processing, memory, and network bandwidth.

4. Rapid elasticity: consumers are able to access tremendous computing power, as well as have the ability to scale resources up and down, as needed.

Users and organizations can adopt cloud computing through three main service models, which are: 1) Infrastructure as a Service, 2) Platform as a Service, and 3) Software as a Service [11, 18]. Infrastructure as a Service (IaaS) is the ability to provide full computer and information technology infrastructure resources, through the Internet, as "service-on-demand" [11]. IaaS provides services to organizations, such as a server, data storage, networking, operating systems, and application software. Platform as a Service (PaaS) is an application development environment that includes tools and operating systems that help users to manage and control infrastructure applications. PaaS uses online, in-cloud services, such as Microsoft's Windows Azure [11]. Software as a Service (SaaS) is just an application delivered through the Internet on a "pay-as-you-go" basis, and as licensed services to 
end-users over the Internet $[7,11,13]$. Further, cloud computing can be described based on an organization's needs, level of security, level of trust, and amount of applicable regulations. In this context, there are three levels of cloud computing forms: 1) public cloud, 2) private cloud, and 3) hybrid. In a public cloud, the cloud computing is outsourced to a third party. In a private cloud, the cloud computing is "insourced" (i.e., implemented internally within an organization). Finally, in the hybrid model, the cloud computing is made up of a combination of outsourced and "insourced" [7].

Through a review of the available literature, the researchers found a gap in the adoption of this new technology. More specifically, many universities are still lagging behind in the adoption of cloud computing, compared to government, and business sectors. These results are surprising in light of the expectations of technology experts that cloud computing will have significant growth in academia, compared to other sectors [20]. Furthermore, many faculty and staff in the academic sector did not have enough data and a clear understanding of the important factors that contribute to making decisions regarding the adoption of new technologies (e.g., cloud computing) [10].

Cloud computing technology appears to be an excellent solution for many universities that struggle with information technology (IT) complexity and cost. At the same time, cloud computing can provide universities with significant flexibility and agility [15]. Cloud computing, as observed in many university experiences, can handle many products and services that are provided by traditional IT departments (e.g., email services, operating systems, PCs, and servers). In addition, cloud computing can offer the IT developer many different tools and options to improve projects (e.g., web applications) [18].

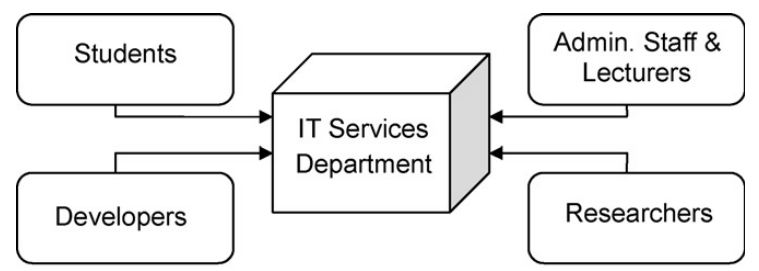

Figure 1. Simplified structure of the main users of IT services in a typical university [18].

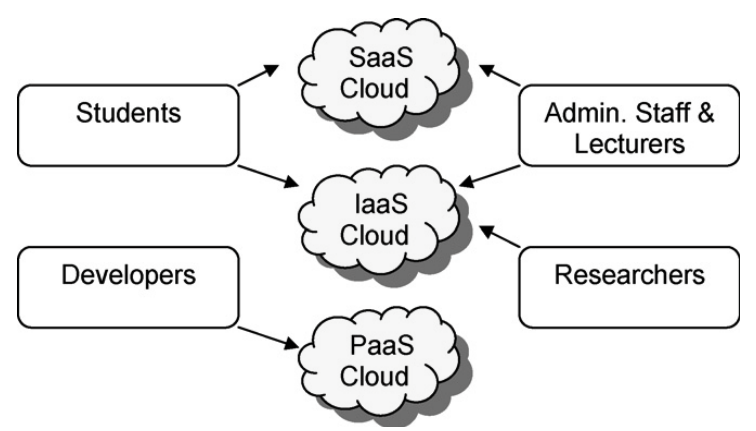

Figure 2. Simplified structure of the main users of IT services in a typical university [18].

\section{RESEARCH QUESTIONS}

This study was undertaken to determine how Computer and Information Systems (CIS) faculty at two institutions of higher education view the use of cloud computing technology. The study identified the internal and external factors that can influence CIS faculty in their use and adoption of cloud computing components. The Developed Technology Acceptance Model (TAM) was used to examine the relationship between CIS faculty and the internal and external factors that can influence decisions to adopt cloud computing [6]. 
Specifically, the study was conducted to answer the following research questions:

1. What is the perception of CIS faculty regarding cloud computing?

2. What are the advantages of using cloud computing in a CIS department?

3. What are the disadvantages of using cloud computing in a CIS department?

4. What are the key factors that influence the decision by CIS faculty to use/adopt cloud computing?

\section{RELATED STUDIES}

Cloud computing offers a variety of services that vary in importance from one organization to another. Most organizations are focused on providing enough cloud computing resources to satisfy users' demands, reduce upfront resource commitments, and allow customers to "pay-as-you-go" for services [2]. Universities are using cloud computing technology to replace traditional software by delivering applications and services through the Internet. The reasons behind the adoption of cloud computing are driven by reductions in Information Technology (IT) costs, reductions in systems complexity, and the opportunity to gain functionality that is more agile and flexible.

According to the CDW annual report [5], a survey of 1,242 information technology professionals found that the number of universities that adopt cloud computing, or plan to adopt cloud computing, has been increasing, compared to the annual report of 2011. The reasons for this increase are the following: a 55\% increase in efficiency, a $49 \%$ improvement in mobility, a $32 \%$ increase in the ability to innovate, a $31 \%$ increase in available IT staff for other projects, a $25 \%$ reduction in IT operating costs, and a $24 \%$ increase in the ability to offer new products/services. Also, the report revealed that $43 \%$ of higher-education institutions are implementing or maintaining cloud computing. This number has increased by $10 \%$, compared to $34 \%$ in 2011 [5].

Recently, many universities in the United States have started to adopt cloud computing, such as the University of California, Washington State University, the University of Washington, the University of Chicago, the University of California at Berkley, Cornell University, the University of Massachusetts at Amherst, and Carnegie Mellon University $[18,19]$. For example, the University of California at Berkley moved one of its courses, which required a huge amount of servers, from their information technology department to cloud computing, hosted by Amazon Web services [8].

Cloud computing helps universities focus on core activities, such as research and innovations, rather than spending time and resources on complex information technology configuration and software systems. Katz et al. defined the most common features cloud computing offers to universities [9]. According to Katz et al., cloud computing ...

1. Increases access to scarce IT expertise and talent.

2. Scales IT services and resources.

3. Promotes further IT standardization.

4. Accelerates the time to market through IT supply bottleneck reductions.

5. Channels or counters the ad-hoc consumer of enterprise IT services.

6. Facilitates the transparent matching of IT costs, demand and funding.

7. Increases interoperability.

8. Supports a model of a $24 \times 7 \times 365$ environment.

9. Enables the sourcing of cycles and storage powered by renewable energy.

10. Drives down capital and total costs of IT in higher education.

The attractive features that are offered by cloud computing have convinced many universities to adopt and take full advantage of this growing technology. For example, North Carolina State University was able to reduce costs and information technology complexity. By outsourcing some in-house services to the cloud, North Carolina State University was able to reduce the campus information technology staff from 15 to 3 employees [22]. However, adoption levels of cloud computing in universities are still much lower than the private, commercial, and governmental sectors [9]. In this paper, the researchers explored the types of cloud computing applications and services that are used by Computer and Information Systems faculty. 


\section{METHODS AND PROCEDURES}

The current study involved the administration of an online survey instrument that consisted of 37 closed-ended questions that was created in QuestionPro Online Survey Software, from QuestionPro, Inc. The survey used Likert items with descriptors of five steps or Likert levels of agreement/disagreement. The Likert items were balanced on both sides of a neutral option, creating a less biased measurement. Specifically, the Likert levels were Strongly Agree (value = 5), Fairly Agree (value = 4), Neutral (value = 3), Partly Disagree (value = 2), and Strongly Disagree (value $=1)$.

This survey was administered during the spring semester of the 2013/2014 academic year to Computer and Information Systems (CIS) faculty at two universities. One university is a private institution located in the United States (Pennsylvania). This institution has a CIS department that consists of 22 faculty members. The other university is public institution located at Asir Province in the southwest region of Saudi Arabia. The Saudi Arabian institution has a CIS department that consists of 19 faculty members. The CIS faculty at both universities completed the online survey, on their own time, and submitted their anonymous results. Out of a total population of 41 CIS faculty members from the two universities, 34 or $82.93 \%$ completed the survey. More specifically, 19 of the 22 CIS faculty from the university in Pennsylvania and 15 of the 19 total CIS faculty from the University in Saudi Arabia completed the survey.

The numbers assigned to Likert-type items on the survey represent a "greater than" relationship and how much greater is not implied. As a result, the Likert-type items fall into the ordinal measurement scale rather than the nominal, the interval, or the ratio scales of data [3]. Allen and Seaman [1] indicate that as an overall rule, mean and standard deviation are unacceptable parameters for descriptive statistics for data that are on ordinal scales, as are any parametric analyses based upon the normal distribution. Instead nonparametric procedures based on rank, range, or the median are appropriate for analyzing ordinal data, as are distribution methods such as frequencies, contingency tables and tabulations. Descriptive statistics recommended for the ordinal measurement scale items include a median or mode rather than a mean for central tendency and frequencies for variability [3]. Therefore, the responses in this survey were analyzed and summarized by the mode rather than the mean. The results for each research question were reported in tabular format that were rank-ordered according to importance. To further simplify the survey data for discussion purposes, several instances of the response categories were combined (e.g., strongly agree, fairly agree, and partly disagree, strongly disagree) into two nominal categories, such as agree/disagree).

\section{RESEARCH RESULTS}

This section presents the findings of the survey participants' responses to the four research questions. The results for each research question are rank-ordered according to importance and are reported in tabular format. Additionally, key findings of this study are illustrated in Figure 1 and Figure 2 in Appendix A. The combined results of the first research question (What is the perception of Computer and Information Systems faculty regarding cloud computing?) are summarized in Table 1.

As Table 1 illustrates, $61.76 \%$ of the respondents Strongly Agreed that Cloud computing is an attractive technology option for a CIS department. Over 52.94\% indicated that using cloud computing technology would increase the efficiency and quality of services. However, $20.59 \%$ or seven of the respondents expressed concerns (partially disagree or strongly disagree) that adopting cloud computing technology would jeopardize information security. 
Table 1. What is the perception of Computer and Information Systems faculty regarding cloud computing?

\begin{tabular}{|c|c|c|c|c|c|c|c|c|c|c|}
\hline \multirow{2}{*}{ Strongly Agree } & \multicolumn{2}{|c|}{ Strongly Agree } & \multicolumn{2}{|c|}{ Fairly Agree } & \multicolumn{2}{|c|}{ Neutral } & \multicolumn{2}{|c|}{$\begin{array}{l}\text { Partially } \\
\text { Disagree }\end{array}$} & \multicolumn{2}{|c|}{$\begin{array}{l}\text { Strongly } \\
\text { Disagree } \\
\end{array}$} \\
\hline & Count & Percent & Count & Percent & Count & Percent & Count & Percent & Count & Percent \\
\hline $\begin{array}{l}\text { Cloud computing is an } \\
\text { attractive technology option } \\
\text { for a CIS department. }\end{array}$ & 21 & $61.76 \%$ & 10 & $29.41 \%$ & 3 & $8.82 \%$ & 0 & $0 \%$ & 0 & $0 \%$ \\
\hline $\begin{array}{l}\text { Increase the efficiency and } \\
\text { quality of services. }\end{array}$ & 18 & $52.94 \%$ & 9 & $26.47 \%$ & 6 & 17.65 & 1 & $2.94 \%$ & 0 & $0 \%$ \\
\hline $\begin{array}{l}\text { I recommended adopting } \\
\text { cloud technology in CIS } \\
\text { department. }\end{array}$ & 14 & $41.18 \%$ & 16 & $47.06 \%$ & 3 & $8.82 \%$ & 1 & $2.94 \%$ & 0 & $0 \%$ \\
\hline $\begin{array}{l}\text { Is an attractive economic } \\
\text { option for a CIS department }\end{array}$ & 13 & $38.24 \%$ & 16 & $47.06 \%$ & 5 & $14.71 \%$ & 0 & $0 \%$ & 0 & $0 \%$ \\
\hline $\begin{array}{l}\text { Increase data information } \\
\text { security. }\end{array}$ & 6 & $17.65 \%$ & 11 & $32.35 \%$ & 10 & $29.41 \%$ & 5 & $14.71 \%$ & 2 & $5.88 \%$ \\
\hline
\end{tabular}

The second research question sought to determine the advantages of using cloud computing. The results from the seven survey questions are summarized in Table 2 .

As the results in Table 2 indicate, accessing data and applications from anywhere/at any time received $76.47 \%$ of the responses in the Strongly Agree category and improving mobility for faculty received $73.53 \%$ of the responses in the Strongly Agree category. Storage capacity and improved backup and recovery were also indicated as advantages. Increased cost savings received the lowest percentage in the Strongly Agree category, but did receive over half of the responses in the Fairly Agree category and half of the respondents felt strongly that reducing IT workload and providing a scalable and flexible environment were advantages. In fact, no respondent strongly disagreed with any of the questions and only two respondents partially disagreed.

Table 2. What are the advantages of using cloud computing in your Computer and Information Systems department?

\begin{tabular}{|c|c|c|c|c|c|c|c|c|c|c|}
\hline \multirow{2}{*}{ Response } & \multicolumn{2}{|c|}{ Strongly Agree } & \multicolumn{2}{|c|}{ Fairly Agree } & \multicolumn{2}{|c|}{ Neutral } & \multicolumn{2}{|c|}{$\begin{array}{l}\text { Partially } \\
\text { Disagree }\end{array}$} & \multicolumn{2}{|c|}{$\begin{array}{l}\text { Strongly } \\
\text { Disagree } \\
\end{array}$} \\
\hline & Count & Percent & Count & Percent & Count & Percent & Count & Percent & Count & Percent \\
\hline $\begin{array}{l}\text { Accessing data/applications } \\
\text { from anywhere/any time } \\
\text { using any device }\end{array}$ & 26 & $76.47 \%$ & 7 & $20.59 \%$ & 1 & $2.94 \%$ & 0 & $0 \%$ & 0 & $0 \%$ \\
\hline Improved Mobility for Users & 25 & $73.53 \%$ & 7 & $20.59 \%$ & 1 & $3 \%$ & 1 & $2.94 \%$ & 0 & $0 \%$ \\
\hline $\begin{array}{l}\text { Provide more storage } \\
\text { capacity/share data/email. }\end{array}$ & 21 & $61.76 \%$ & 11 & $32.35 \%$ & 2 & $5.88 \%$ & 0 & $0 \%$ & 0 & $0 \%$ \\
\hline $\begin{array}{l}\text { Improved data backup } \\
\text { /disaster recovery }\end{array}$ & 20 & $58.82 \%$ & 11 & $32.35 \%$ & 2 & $5.88 \%$ & 1 & $3 \%$ & 0 & $0 \%$ \\
\hline $\begin{array}{l}\text { Reduced IT } \\
\text { complexity/workload }\end{array}$ & 17 & $50.00 \%$ & 9 & $24.47 \%$ & 8 & $23.53 \%$ & 0 & $0 \%$ & 0 & $0 \%$ \\
\hline $\begin{array}{l}\text { Provide working } \\
\text { scalability/flexibility } \\
\text { environment }\end{array}$ & 17 & $50.0 \%$ & 11 & $32.35 \%$ & 6 & $17.65 \%$ & 0 & $0 \%$ & 0 & $0 \%$ \\
\hline Increased cost savings & 14 & $41.18 \%$ & 18 & $52.94 \%$ & 2 & $5.88 \%$ & 0 & $0 \%$ & 0 & $0 \%$ \\
\hline
\end{tabular}

The third research question sought to determine the disadvantages of using cloud computing. The results from these survey questions are summarized in Table 3. 
Most research participants (94.11\%) selected Strongly Agree or Fairly Agree in relation to the questions regarding $a$ lack of standards among cloud service providers. A second concern was with Integration with current networks/applications/systems, where $76.47 \%$ strongly or fairly agreed and 55.88\% Strongly Agree or Fairly Agreed with System performance of cloud services.

The responses were distributed almost evenly with regard to the last two questions in the table: a lack of reliability and a lack of availability. This distribution can be seen by combining the columns for both questions (Strongly Agree and Fairly Agree), as well as (Partially and Strongly Disagree). In the case of lack of reliability, the breakdown for the three columns is $32.35 \%$ (Agree combination), 32.35\% (Neutral) and $35.29 \%$ (Disagree combination). Regarding the lack of availability question, the breakdown for the three columns is $35.30 \%$ (Agree combination), 29.41\% (Neutral), and 35.29\% (Disagree combination).

Finally, in regard to the question security of propriety data and applications, $70.59 \%$ strongly or fairly agreed. This concern was previously indicated (Table 1) by the respondents in their perceptions that adopting cloud computing technology would increase data information security risks.

Table 3. What are the disadvantages of using cloud computing in Computer and Information Systems department?

\begin{tabular}{|c|c|c|c|c|c|c|c|c|c|c|}
\hline \multirow{2}{*}{ Response } & \multicolumn{2}{|c|}{ Strongly Agree } & \multicolumn{2}{|c|}{ Fairly Agree } & \multicolumn{2}{|c|}{ Neutral } & \multicolumn{2}{|c|}{$\begin{array}{l}\text { Partially } \\
\text { Disagree } \\
\end{array}$} & \multicolumn{2}{|c|}{$\begin{array}{l}\text { Strongly } \\
\text { Disagree }\end{array}$} \\
\hline & Count & Percent & Count & Percent & Count & Percent & Count & Percent & Count & Percent \\
\hline $\begin{array}{l}\text { Lack of standards among } \\
\text { cloud service providers }\end{array}$ & 21 & $61.76 \%$ & 11 & $32.35 \%$ & 2 & $5.88 \%$ & 0 & $0 \%$ & 0 & $0 \%$ \\
\hline $\begin{array}{l}\text { Concerns with security of } \\
\text { proprietary data/ applications }\end{array}$ & 16 & $47.06 \%$ & 8 & $23.53 \%$ & 7 & $20.59 \%$ & 3 & $8.82 \%$ & 0 & $0 \%$ \\
\hline $\begin{array}{l}\text { Integration with current } \\
\text { networks/applications/systems }\end{array}$ & 11 & $32.35 \%$ & 15 & $44.12 \%$ & 7 & $20.59 \%$ & 1 & $2.94 \%$ & 0 & $0 \%$ \\
\hline $\begin{array}{l}\text { System performance of cloud } \\
\text { services }\end{array}$ & 11 & $32.35 \%$ & 8 & $23.53 \%$ & 9 & $26.47 \%$ & 4 & $11.76 \%$ & 2 & $5.88 \%$ \\
\hline $\begin{array}{l}\text { Legal and regulatory } \\
\text { compliance }\end{array}$ & 8 & $23.53 \%$ & 5 & $14.71 \%$ & 14 & $4.18 \%$ & 6 & $17.65 \%$ & 1 & $2.94 \%$ \\
\hline Lack of reliability & 7 & $20.59 \%$ & 4 & $11.76 \%$ & 11 & $32.35 \%$ & 8 & $23.53 \%$ & 4 & $11.76 \%$ \\
\hline Lack of availability & 5 & $14.71 \%$ & 7 & $20.59 \%$ & 10 & $29.41 \%$ & 8 & $23.53 \%$ & 4 & $11.76 \%$ \\
\hline
\end{tabular}

Finally, the fourth research question sought to determine the key factors that influence the decision by Computer and Information systems faculty to use or adopt cloud computing Computer and Information Systems departments. The results from these survey questions are summarized in Table 4.

Over 75\% Strongly Agreed that they would be willing to learn cloud computing services and tools. One respondent did, however, did indicate that they were not willing to learn cloud computing. When examining the question regarding enhancing effectiveness on the job, almost two thirds of the respondents (63.16\%) were Neutral and two respondents Partially Disagreed. Finally, 41.81\% responded as Neutral on whether or not the use of cloud computing would make their job easier. 
Table 4. What are the key factors that influence Computer and Information Systems faculty in relation to adopting/using cloud computing?

\begin{tabular}{|c|c|c|c|c|c|c|c|c|c|c|}
\hline \multirow{2}{*}{ Response } & \multicolumn{2}{|c|}{ Strongly Agree } & \multicolumn{2}{|c|}{ Fairly Agree } & \multicolumn{2}{|c|}{ Neutral } & \multicolumn{2}{|c|}{$\begin{array}{l}\text { Partially } \\
\text { Disagree }\end{array}$} & \multicolumn{2}{|c|}{$\begin{array}{l}\text { Strongly } \\
\text { Disagree }\end{array}$} \\
\hline & Count & Percent & Count & Percent & Count & Percent & Count & Percent & Count & Percent \\
\hline $\begin{array}{l}\text { I would be willing to learn } \\
\text { to use cloud computing } \\
\text { services, application and } \\
\text { tools. }\end{array}$ & 26 & $76.47 \%$ & 5 & $14.71 \%$ & 2 & $5.88 \%$ & 0 & $0 \%$ & 1 & $2.94 \%$ \\
\hline $\begin{array}{l}\text { It would be easy for me to } \\
\text { become skillful at using the } \\
\text { cloud computing application } \\
\text { and tools. }\end{array}$ & 15 & $44.12 \%$ & 13 & $38.24 \%$ & 6 & $17.65 \%$ & 0 & $0 \%$ & 0 & $0 \%$ \\
\hline $\begin{array}{l}\text { Enables me to accomplish } \\
\text { tasks more quickly. }\end{array}$ & 15 & $44.12 \%$ & 9 & $26.47 \%$ & 9 & $26.47 \%$ & 1 & $2.94 \%$ & 0 & $0 \%$ \\
\hline $\begin{array}{l}\text { Increases my productivity in } \\
\text { my job. }\end{array}$ & 12 & $35.29 \%$ & 13 & $38.24 \%$ & 7 & $20.59 \%$ & 2 & $5.88 \%$ & 0 & $0 \%$ \\
\hline Makes it easier to do my job & 11 & $32.35 \%$ & 7 & $20.59 \%$ & 14 & $41.81 \%$ & 2 & $5.88 \%$ & 0 & $0 \%$ \\
\hline $\begin{array}{l}\text { Cloud computing } \\
\text { applications and tools would } \\
\text { be flexible with which to } \\
\text { interact. }\end{array}$ & 10 & $29.41 \%$ & 15 & $44.12 \%$ & 7 & $20.59 \%$ & 2 & $5.88 \%$ & 0 & $0 \%$ \\
\hline $\begin{array}{l}\text { Enhances my effectiveness } \\
\text { on the job. }\end{array}$ & 10 & $29.41 \%$ & 8 & $23.53 \%$ & 14 & $63.16 \%$ & 2 & $10.53 \%$ & 0 & $0 \%$ \\
\hline
\end{tabular}

\section{CONCLUSIONS}

Cloud computing is largely an evolution of Information Technology (IT) that is maturing from a promising business concept to one of the fastest growing segments of the IT industry. Moving academic IT services to the cloud may involve a formidable decision, since the use of cloud computing can change the sourcing and delivery of solutions. The current study was based on the views of 34 faculty members in the Computer and Information Systems (CIS) departments of two universities. This study explored the faculty's perceptions of the impact and effectiveness of using cloud computing technology. Of the 34 survey respondents, 32 or $94.11 \%$ indicated that they were knowledgeable or somewhat knowledgeable of cloud computing. Two respondents indicated that they were not very knowledgeable, and no respondent indicated that they had no knowledge of cloud computing.

Overall, the responses by the CIS faculty at both universities were positive and view cloud computing as an attractive technology option for a CIS department. Furthermore, 31 or $91.18 \%$ of the respondents indicated that they would be willing to learn cloud computing services, applications, and tools. Additionally, according to the responses, several of the services or applications that faculty would like to see migrated to the cloud were messaging conferencing and collaboration storage, office/ productivity suites, and the hosting of internally-developed software by external hosts. Finally, when asked about the overall status of cloud computing within CIS departments, $48 \%$ indicated that cloud computing technology was under discussion and/or in the planning stages and $14 \%$ indicated that cloud services were already in use.

However, as presented in the results section (94.11\%) responded Strongly Agree or Fairly Agree in relation to the questions regarding a lack of standards among cloud service providers. A second concern was with Integration with current networks/applications/systems, where $76.47 \%$ strongly or fairly agreed and $70 \%$ of the faculty had concerns that adopting cloud computing technology would increase data information security risks.

In conclusion, a unique aspect of the current study is the involvement of two very different institutes of higher education. As stated previously, this study involved a medium-sized university in Pennsylvania, and a mediumsized university in the Southwest region of Saudi Arabia. These two institutions not only differ in geography, but 
also in language, culture, climate, economics, political structure, etc. As a topic of future research, the authors of this study plan to perform a comparative study between the two schools to determine if there is a significant difference in preferences among the faculty regarding various course delivery formats.

\section{REFERENCES}

1. Allen, E, \& Seaman, C, (2007) Likert Scales and Data Analysis. Retrieved from: http://mail.asq.org/qualityprogress/2007/07/statistics/likert-scales-and-data-analyses.htm

2. Armbrust, Michael, et al., Above the Clouds: A Berkeley View of Cloud Computing, Technical Report No. UCB/EECS-2009028, February 10, 2009, at http://www.eecs.berkeley.edu/Pubs/TechRpts/2009/EECS-200928.html

3. Boone, Harry A.,\& Boone, Deborah A. (2012). Analyzing Likert Data. Journal of Extension [On-line], 50(2) Article 2TOT2. Available at http://www.joe.org/joe/2012april/tt2.php.

4. Campbell, Steve. (2009). TimeSharing 2.0. HPC Wire. Retrieved from: http://www.hpcwire.com/hpcwire/2009-11-03/timesharing_2_0.html

5. CDW's 20130 State of the Cloud Computing Report, CDW LLC. Retrieved from: http://www.cdwnewsroom.com/wpcontent/uploads/2013/02/CDW_2013_State_of_The_Cloud_Report_021113_FINAL.pdf

6. Davis, F. D. (1989). Perceived usefulness, perceived ease of use, and user acceptance of Information technology, MIS Quarterly, 13(3), 319-340. Retrieved from: http://iris.nyit.edu/ kkhoo/Spring2008/Topics/TAM/PercieveUsefulness_MIS.pdf

7. Etsebeth E. (2012). Trialability, perceived risk and complexity of understanding as determinants of cloud computing services adoption. University of Pretoria. Retrieved from:http:/upetd.up.ac.za/thesis/available/etd02162013-162613/unrestricted/dissertation.pdf

8. Fox, A. (2009). Cloud computing in education. Berkeley iNews, https://inews. berkeley.edu/articles/Spring2009/cloud-computing (accessed on: 29 July 2009).

9. Katz, R. N., Goldstein, P. J. \& Yanosky, R. (2009). Demystifying cloud computing for higher education, EDUCAUSE Center for Applied Research Bulletin, 19, 1-13.

10. Lease D. (2005). Factors Influencing the Adoption Of Biometric Security Technologies By Decision Making Information Technology And Security Managers. Capella University. Retrieved from: http://drdavidlease.com/uploads/David_Lease_UMI_Dissertation.pdf

11. Leavitt, N. (2009). Is cloud computing really ready for prime time, 42(1), 15-20.

12. Stroh, S., Acke, R. O., \& Kumar, A. (2009) The Cloud is Ready for you, Are you ready for Cloud?, Retrieved from: www.booz.com/media/file/Cloud_Is_Ready_for_You.pdf

13. Limbasan, Adriana. (2011). Implementing SaaS Solution for CRM. Informatica Economica. Retrieved from: http://www.readperiodicals.com/201104/2444603581.html

14. Mustafee, N. (2010). "Exploiting Grid Computing, Desktop Grids and Cloud Computing for e- Science Future Directions." Transforming Government: People, Process and Policy, 4(4): 288-298; DOI: 10.1108/17506161011081291. Retrieved from: http://www.emeraldinsight.com/journals.htm?articleid=1889786\&show=abstract

15. Nicholson J. (2009). Cloud Computing's Top Issues for Higher Education. University Business. Retrieved from: http://www.universitybusiness.com/article/cloud-computings-top-issues-higher-education

16. Opala, Omondi. (2012). An analysis of security, cost-effectiveness, and IT compliant factors influencing cloud adoption by managers. Capella University. Retrieved from: http://gradworks.umi.com/35/27/3527699.html

17. Ross, Verginia. (2010). Factors influencing adoption of cloud computing by decision making managers. Capella University.

18. Sultan, N. (2010). "Cloud Computing for Education: A New Dawn?," International Journal of Information Management, 30, 109-116

19. SUNNYVALE, Calif., Apr 09, 2009 (BUSINESS WIRE) -- Yahoo! Inc. (Nasdaq: YHOO) The State of Cloud Computing in Higher Education. (2013). New survey highlights key opportunities for colleges.

20. "The NIST Definition of Cloud Computing" (2011) National Institute of Standards and Technology.

21. Venkatesh, V.; Morris; Davis; Davis (2003), "User Acceptance of Information Technology: Toward a Unified View", MIS Quarterly 27 (3), pp. 425-478. Retrieved from: 
http://citeseerx.ist.psu.edu/viewdoc/download;jsessionid=4D8A074FFC4029AFFBF306475CEBB469?doi=10 .1.1.197.1486\&rep $=$ rep $1 \&$ type $=$ pdf

22. Wyld, D. C. (2011). "Cloud Computing 101: Universities are Migrating to The Cloud for Functionality and Savings," Retrieved from: http://rolandstuart615.wordpress.com/2011/10/13/cloud-computing-101universities-are-migrating-to-the-cloud-for-functionality-and-savings/ 


\section{APPENDIX A}

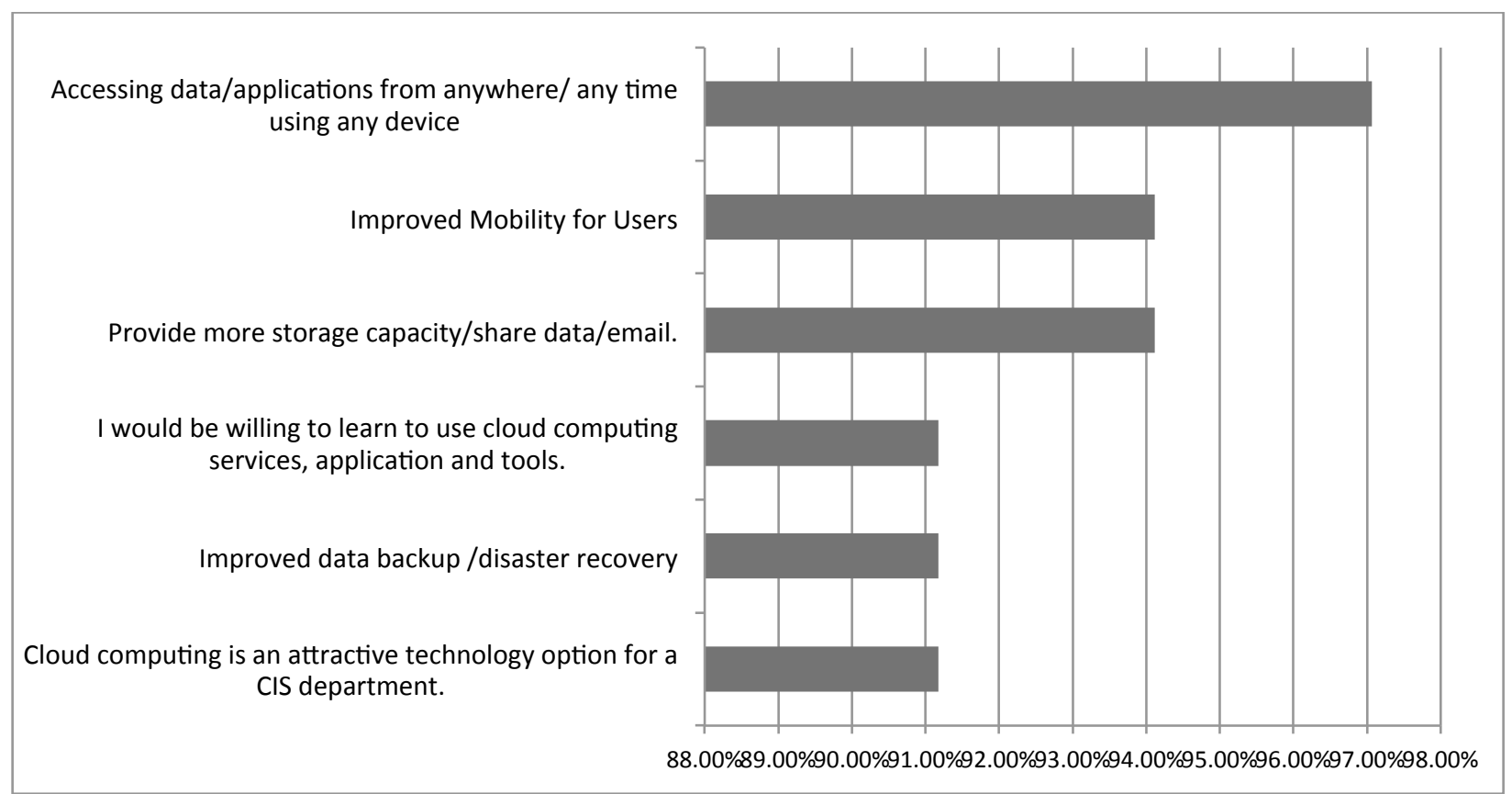

Figure 1. Five Highest Key Items When Combining Strongly Agree and Partially Agree

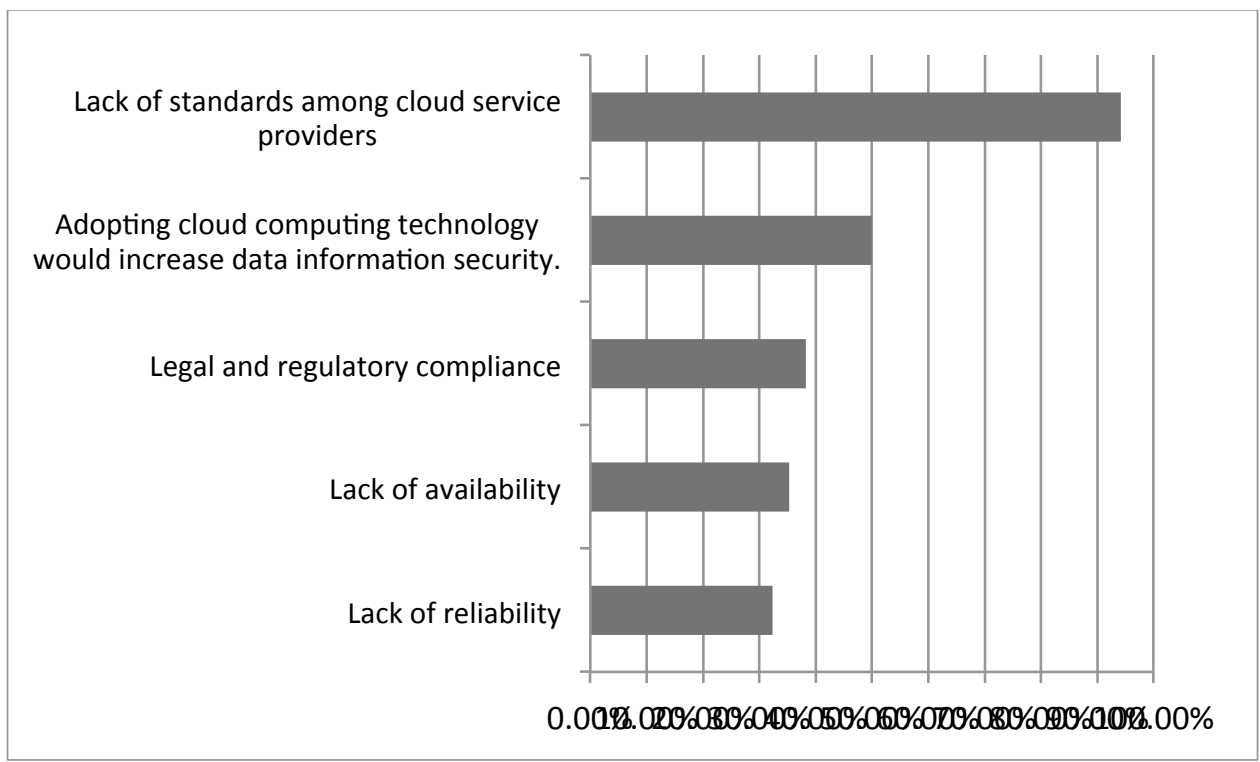

Figure 2. Five Lowest Key Items When Combining Strongly Agree and Partially Agree 